\title{
Should computed tomography (CT) be used as a screening or follow-up tool for asymptomatic patients with SARS-CoV-2 infection?
}

\author{
Yanwei Zeng ${ }^{1,2 \#}$, Junyan Fu ${ }^{1,2 \#}$, Xiaohong Yu ${ }^{3}$, Zhijun Huang ${ }^{4}$, Xuyang Yin ${ }^{1,2}$, Daoying Geng ${ }^{1,2}$, Jun Zhang ${ }^{1,2}$ \\ ${ }^{1}$ Department of Radiology, Huashan Hospital, ${ }^{2}$ Institute of Functional and Molecular Medical Imaging, Fudan University, Shanghai 200040, China; \\ ${ }^{3}$ Department of Radiology, Yiyang Fourth People's Hospital, Yiyang 413000, China; ${ }^{4}$ Department of Radiology, Shaodong People's Hospital, \\ Shaodong 422800, China
}

\#These authors contributed equally to this work.

Correspondence to: Jun Zhang. Department of Radiology, Huashan Hospital, Fudan University, No. 12 Wulumuqi Road (Middle), Shanghai 200040, China; Institute of Functional and Molecular Medical Imaging, Fudan University, No. 12 Wulumuqi Road (Middle), Shanghai 200040, China. Email: zhj81828@163.com.

Submitted Mar 23, 2020. Accepted for publication Apr 09, 2020.

doi: 10.21037/qims.2020.04.10

View this article at: http://dx.doi.org/10.21037/qims.2020.04.10

\section{Introduction}

The corona virus disease 2019 (COVID-19), caused by the severe acute respiratory syndrome corona virus 2 (SARSCoV-2), was first reported in China in December 2019. As of $10 \mathrm{AM}$ on March 28, 2020, there have been 571,678 confirmed patients and 26,494 deaths around the world, and the affected area is still expanding (1). The gold standard for the diagnosis of COVID-19 is the real-time reverse transcriptase-polymerase chain reaction (RT-PCR) assay of the pharyngeal swab specimen. However, due to its inadequate test kit in some areas, computed tomography (CT) examination has been used as a screening and followup tool in China (2,3). Symptomatic patients with negative initial RT-PCR detection might show lesions on CT (4). There are mainly four types of intrapulmonary lesions of COVID-19 including pure ground-glass opacity (GGO), GGO lesions with reticular and/or interlobular septal thickening, GGO with consolidation, GGO with reticular and/or interlobular septal thickening. Pulmonary lesions are frequently confined to the peripheral area of the lungs and involved bilateral lungs with the right lower lobe most affected $(5,6)$. Mediastinal lymphadenopathy, pleural effusion, pulmonary emphysema and other signs are rare.

However, CT examination has the disadvantage of radiation dose and COVID-19 can be self-limiting. Bernheim et al. (7) reported that CT was normal in $56 \%$ of patients within 0-2 days after symptoms appeared, indicating that CT was thereby unlikely a reliable standalone tool to rule out COVID-19 infection. Xu et al. (8) reported two asymptomatic children and adolescent RTPCR confirmed patients (50\% of their family cluster cases) had no lesion both on initial and follow-up CT. Wáng (9) pointed out that in the general population, the proportion of patients with no or few symptoms would be larger, and the positive rate of CT would be lower, but such rate in asymptomatic patients is still unknown. Therefore, the application of CT in screening and the follow-up of asymptomatic COVID-19 patients is controversial.

\section{Case presentation}

We reviewed in total 7 patients who were asymptomatic throughout the course from the 99 consecutive patients with COVID-19, diagnosed by the real-time RT-PCR assay of the pharyngeal swab specimen, of three hospitals (Huashan Hospital of Fudan University, Fourth People's Hospital of Yiyang and People's Hospital of Shaodong) in China from January 23, 2020 to February 20, 2020. The clinical and CT features were collected in Table 1. Among them, the number 
Table 1 Basic information and CT findings of patients

\begin{tabular}{lccccccc}
\hline Number & $\begin{array}{c}\text { Age } \\
\text { (years) }\end{array}$ & Gender & $\begin{array}{c}\text { First CT } \\
\text { scan }\end{array}$ & $\begin{array}{c}\text { Interval } \\
\text { (days) }\end{array}$ & Second CT scan & $\begin{array}{c}\text { Interval } \\
\text { (day) }\end{array}$ & Third CT scan \\
\hline 1 & 17 & Female & No lesions & 7 & No lesions & - & - \\
2 & 49 & Female & No lesions & 3 & No lesions & - & No lesions \\
3 & 15 & Male & No lesions & 7 & No lesions & 3 & No lesions \\
4 & 22 & Female & No lesions & 7 & GGO with reduced size and density in the left \\
5 & 46 & Female & No lesions & 7 & GGO in the left lower lobe with & 3 & G lower lobe with the maximum area of 80 mm ${ }^{2}$ \\
6 & 22 & Female & - & - & - & - & -
\end{tabular}

GGO, ground-glass opacity.
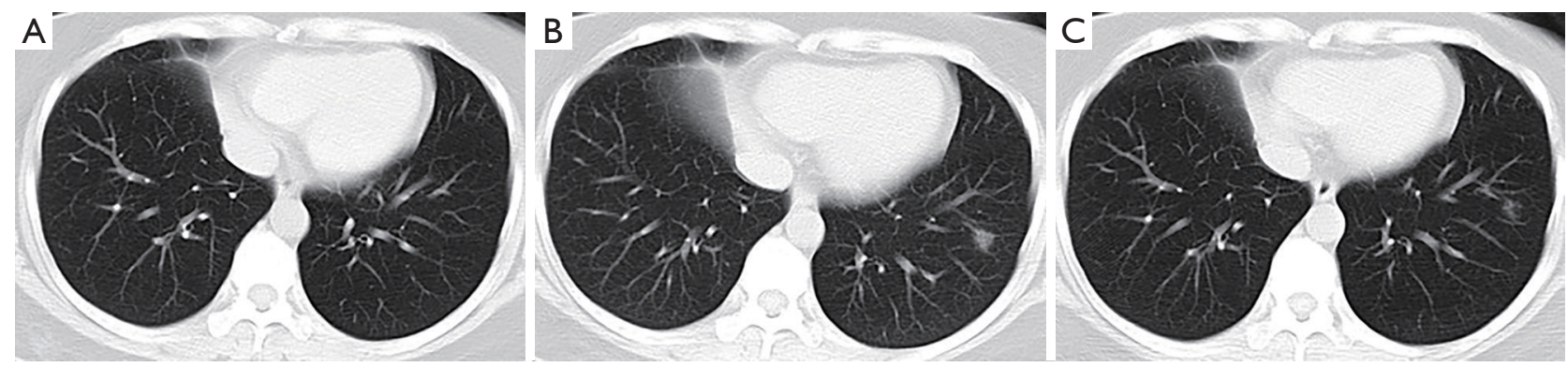

Figure 1 CT images of patient 5. A 46-year-old female who was asymptomatic throughout the course, with the following results of laboratory test: decreased white blood cell count $\left(3.73 \times 10^{9} / \mathrm{L}\right)$, decreased percent of neutrophils $(39.20 \%)$, increased percent of lymphocytes (50.11\%), and normal liver function test and myocardial enzyme measurement. Antiviral therapy was used. The chest CT scan (A) was performed 1 day after the real-time RT-PCR assay, and no lesion was showed in the lung. After 10 days, a ground glass opacity was noted with a maximum cross-sectional area of about $110 \mathrm{~mm} 2$ in the lower lobe of the left lung (B). Furthermore, intravenous infusion of gamma globulin was used for treatment. Three days later, the lesion reduced in size and density (C).

and size (in the section with the largest area of the lesion) of lesions were evaluated by two radiologists with more than 10 years of diagnostic experience in chest CT. In our study, there were 6 female and 1 male included, with a mean age of 32 years old (range, 17-50 years). Five patients came from the same hospital, and the initial CT scan and the RT-PCR assay were performed at the same day. They had follow-up CT scans once or twice (the last CT examinations were all performed after real-time RT-PCR test turned negative). There were no lesions of COVID-19 in the initial and follow-up chest CT of 4 patients. The remaining one presented a small ground glass opacity 6 days after the initial CT, but the lesion became smaller with deceased density 4 days later (Figure 1). Another two asymptomatic patients in the other hospitals were treated with antiviral therapy and remained asymptomatic until real-time RT-PCR test turned negative and they didn't undergo CT examination.

\section{Discussion}

In this review, we found five asymptomatic patients with SARS-CoV-2 infection showed no or few abnormalities on CT examination throughout the course of the disease. It suggested that when the patient is asymptomatic, the lungs may not be involved or be less so. And the other two asymptomatic patients, who did not have CT examination through the whole course of the disease, had antiviral treatment after diagnosis and were discharged after the nucleic acid test turned negative. Although CT is an important tool to evaluate the condition of patients, the indications for CT are not completely clear 
until now. The cases inspired us that maybe for asymptomatic patients, isolation and antiviral treatment can be adopted, and CT is not necessary so as not to increase the patient's physical and economic burden.

To sum up, the role of CT in COVID-19 patient's management course remains undefined and its application as a diagnostic tool may be unjustified among regions with low COVID-19 prevalence (low pre-CT test probability) (10). In addition, CT carries a risk of cancer and there is another risk of cross-infection between infected and uninfected patients. CT examination may not be necessary as a screening tool for asymptomatic suspicious patients with SARS-CoV-2 infection, nor as a follow-up tool for asymptomatic confirmed patients.

\section{Acknowledgments}

Funding: This study was supported by the National Natural Science Foundation of China (No. 81971598), Shanghai Shuguang Program (No. 19SG06) and Shanghai Municipal Commission of Health and Family Planning (No. 2017BR003).

\section{Footnote}

Conflicts of Interest: All authors have completed the ICMJE uniform disclosure form (available at http://dx.doi. org/10.21037/qims.2020.04.10). The authors have no conflicts of interest to declare.

Informed Consent: Written informed consent was obtained from the patients for publication of this manuscript and any accompanying images. A copy of the written consent is available for review by the Editor-in-Chief of this journal.

Open Access Statement: This is an Open Access article distributed in accordance with the Creative Commons Attribution-NonCommercial-NoDerivs 4.0 International License (CC BY-NC-ND 4.0), which permits the noncommercial replication and distribution of the article with the strict proviso that no changes or edits are made and the original work is properly cited (including links to both the formal publication through the relevant DOI and the license). See: https://creativecommons.org/licenses/by-nc-nd/4.0/.

\section{References}

1. World Health Organization. Coronavirus disease 2019
(COVID-19) Situation report - 68. Published March 28, 2020. Available online: https://www.who.int/docs/defaultsource/coronaviruse/situation-reports/20200328-sitrep68-covid-19.pdf?sfvrsn=384bc74c_2

2. Fang $Y$, Zhang $H$, Xie J, Lin M, Ying L, Pang P, Ji W. Sensitivity of Chest CT for COVID-19: Comparison to RT-PCR. Radiology 2020. [Epub ahead of print]. doi: 10.1148/radiol.2020200432.

3. Ai T, Yang Z, Hou H, Zhan C, Chen C, Lv W, Tao Q, Sun Z, Xia L. Correlation of Chest CT and RT-PCR Testing in Coronavirus Disease 2019 (COVID-19) in China: A Report of 1014 Cases. Radiology 2020. [Epub ahead of print]. doi: 10.1148/radiol.2020200642.

4. Xie X, Zhong Z, Zhao W, Zheng C, Wang F, Liu J. Chest CT for Typical 2019-nCoV Pneumonia: Relationship to Negative RT-PCR Testing. Radiology 2020. [Epub ahead of print]. doi: 10.1148/radiol.2020200343.

5. Song F, Shi N, Shan F, Zhang Z, Shen J, Lu H, Ling Y, Jiang Y, Shi Y. Emerging 2019 novel coronavirus (2019nCoV) pneumonia. Radiology 2020;295:210-7.

6. Chung M, Bernheim A, Mei X, Zhang N, Huang M, Zeng X, Cui J, Xu W, Yang Y, Fayad Z, Jacobi A, Li K, Li S, Shan H. CT Imaging Features of 2019 Novel Coronavirus (2019-nCoV). Radiology 2020;295:202-7.

7. Bernheim A, Mei X, Huang M, Yang Y, Fayad Z, Zhang N, Diao K, Lin B, Zhu X, Li K, Li S, Shan H, Jacobi A, Chung M. Chest CT Findings in Coronavirus Disease-19 (COVID-19): Relationship to Duration of Infection. Radiology 2020. [Epub ahead of print]. doi: 10.1148/ radiol.2020200463.

8. Xu R, Du M, Li L, Zhen Z, Wang H, Hu X. CT imaging of one extended family cluster of corona virus disease 2019 (COVID-19) including adolescent patients and "silent infection”. Quant Imaging Med Surg 2020;10:800-4.

9. Wáng YXJ. A call for caution in extrapolating chest CT sensitivity for COVID-19 derived from hospital data to patients among general population. Quant Imaging Med Surg 2020;10:798-9.

10. Wang YXJ, Liu WH, Yang M, Chen W. The role of CT for Covid-19 patient's management remains poorly defined. Ann Transl Med 2020;8:145.

Cite this article as: Zeng Y, Fu J, Yu X, Huang Z, Yin X, Geng D, Zhang J. Should computed tomography (CT) be used as a screening or follow-up tool for asymptomatic patients with SARS-CoV-2 infection? Quant Imaging Med Surg 2020;10(5):1150-1152. doi: 10.21037/qims.2020.04.10 